\title{
Parametric study of crushing parameters and failure patterns of pultruded composite tubes using cohesive elements and seam Part I -Central delamination and triggering modelling
}

\author{
Sivakumar Palanivelu $\mathrm{u}^{\mathrm{a}}$, Wim Van Paepegem ${ }^{\mathrm{a}}$, Joris Degrieck $k^{\mathrm{a}}$, Dimitrios Kakogiannis ${ }^{\mathrm{b}}$, Johan Van Ackeren ${ }^{\mathrm{b}}$, \\ Danny Van Hemelrijck ${ }^{\mathrm{b}}$, Jan Wastiels ${ }^{\mathrm{b}}$, John Vantomme ${ }^{\mathrm{c}}$ \\ ${ }^{a}$ Department of Materials Science and Engineering, Ghent University, Sint-Pietersnieuwstraat 41, 9000 Gent, \\ Belgium \\ ${ }^{b}$ Department of Mechanics of Materials and Constructions, Vrije Universiteit Brussel, Pleinlaan 2 B-1050 \\ Brussels, Belgium \\ ${ }^{\mathrm{c}}$ Royal Military Academy, Civil and Materials Engineering Department, Building G, Level 0, 8 Av. Hobbema \\ B-1000, Brussels, Belgium
}

\begin{abstract}
Typically, most of the brittle composite tubes exhibit circumferential delamination, lamina bending, axial cracking and brittle fracturing when subjected to static and dynamic loading conditions. In this work, a new innovative approach was adopted to model the above said failure modes using cohesive elements under an axial impact loading case. The circular and square cross sectional pultruded profiles made of glass-polyester were considered for the study. A numerical parametric study has been conducted to study the effect of the delamination on the failure patterns and the corresponding energy absorption using a single layer and two layers of shell elements. To predict the peak crushing load and the energy absorption, the importance of the adequate numerical modelling of triggering is discussed. All numerical simulations were carried out using the commercially available finite element code ABAQUS V6.7-3 Explicit. Finally, the results of this comprehensive numerical investigation are compared with previously published experimental results [1]. Part II of this paper deals with the influence of multiple delaminations and modelling of axial cracks on the deformation patterns and the effect of initial geometric imperfections on the energy absorption.
\end{abstract}

KEYWORDS: Energy absorption; Composite tubes; Triggering mechanism; Peak crushing load; Delamination; Cohesive element.

\section{Introduction}

A wide spectrum of high speed engineering applications needs to satisfy certain safety regulations. The modern civil and military aviation, ship industry and the automobile industry are the prime examples. The demand made by these industries for materials which are light and strong has been the main motivating factor for the development of new materials. Furthermore, there are some applications in which the products are exposed to extreme environmental conditions such as heat, chemical wear and corrosion. Many studies have proved that composite materials offer good solutions to the above mentioned applications. Furthermore, composite materials have a relative advantage in terms of the specific energy absorption, strength and stiffness. The increased use of these materials has led to the development of the knowledge of the behaviour of the composite structures. This paper focuses on the numerical energy absorption behaviour of composite tubes under an axial impact loading condition.

The energy absorption characteristics of various composite structural elements have been experimentally and theoretically studied by several researchers [1-7]. Different tube cross sections are employed to get the maximum energy absorption with least material investment. However, the energy absorption characteristics of the composite tubes are not only depending on the shape of the tubes [8]. Various variables control the energy absorption of the composite structures. The crushing process depends upon mechanical properties of the fibre and the matrix, fibre volume fraction, laminate stacking sequence, fibre architecture and the

*Corresponding author: Sivakumar Palanivelu, Tel: +32-(0)9-264.33.15, Fax: +32-(0)9- 
geometry of the tube. To decelerate the impactor, the failed tubes exhibit transverse shearing, lamina bending and local buckling crushing modes. Fracturing of the laminates is also a major contributor for the energy absorption during a crushing process [1].

Often conducting a full scale experiment is an expensive affair. Hence an alternative predictive technique to assess the energy absorption of a composite material is very important. The numerical simulation using the finite element technique has been adopted in a few cases to study the energy absorption. The static and dynamic axial collapse of CFRP tubes was well studied numerically in [9]. The numerical energy assessment of hybrid tubes made of pultruded tube overwrapped by braiding was studied by Han and his co-workers [10]. The peak load and the corresponding energy absorption characteristics of a square sandwich composite vehicle hollow body shell were discussed in ref [11]. The progressive crushing of the carbon fibre reinforced structural components of a Formula one racing car was studied in detail in [12]. Most of the above numerical modelling of the composite tubes was done with a single layer of shell elements. However, the numerical modelling of the delamination which causes the split of outer and inner plies of the composite tubes cannot be modelled with a single layer of shell elements. The consideration of the delamination approach is important to predict the energy absorption because it causes the separation of plies and loss in bending stiffness of each sub laminate. Furthermore, many experimental studies [1, 3, 7, 13-15] have proved that the occurrence of the peak load corresponds to the start of the circumferential delamination. Hence, to understand the importance of the delamination and to achieve the typical failure patterns of a brittle composite tube, a numerical parametric study is conducted in this paper with a single layer and two layers of shell elements with cohesive elements. The cohesive fracture model was also used to capture the delamination between the composite plies.

For any cross sectional tubes, an initiator is required to induce the initial stable progressive crushing at low peak load. Generally these initiators are called "triggering mechanisms". The importance of these triggering mechanisms and their effects on the energy absorption are studied experimentally in $[1,16]$. Out of the many triggering mechanisms studied, the $45^{\circ}$ edge chamfering was used by many researchers [1, 7, 8, 17-19]. Normally, the $45^{\circ}$ edge chamfering can be directly modelled numerically by the solid elements. However, the typical failure mechanisms of a brittle composite tube such as central delamination, bending of petals and axial cracks are hard to capture with the solid elements. Due to the above fact researchers have employed the shell elements for their numerical study of composite tubes. Unlike the solid elements, the $45^{\circ}$ edge chamfering is tedious to model with the shell elements. In this work, an investigation was carried out with the shell elements to address triggering modelling issue which has a vital role to predict the correct peak crushing load of a composite tube. Two types of triggering were chosen to study the numerical modelling effect on the peak load and the corresponding energy absorption.

Strength based failure criteria are commonly used to predict the failures in a composite material. Few ply failure models have been proposed that can predict the failures for any given state of loading. Generally, for the impact and the crash analysis of a composite material, the approach of the continuum damage mechanics is preferred in which the failure is first identified and consequently, the degradation of the elastic properties are computed till final fracture. A good example of the above approach can be found in [20], in which a user material model was implemented in the explicit finite element code LS-DYNA to capture the tensile and compressive response of a braided composite material. However, there have been several studies proving that the well established and existing models available in commercial 
finite element codes can be adopted to predict the energy absorption behaviour of a composite tube. Han et al. [10] and Zarei et al. [21] used Material model 54 of LS-DYNA to predict the failure patterns and the energy absorption of the circular and square crosssectional tubes respectively. Material model 54 [22] has the option of using either the Tsai$\mathrm{Wu}$ failure or the Chang-Chang failure criteria for the individual lamina. The Chang-Chang failure criterion is the modified theory of the Hashin's failure criterion which accounts for the non-linear stress-strain behaviour. Although many failure criteria are used, the failure criterion proposed by Hashin [23] is extensively employed in many applications. Hence, in this work the same failure criterion was adopted to assess the energy absorption behaviour of the composite tubes. Many studies [1, 5, 7, 24] have proven that the shape of the composite structures affect the energy absorption values of those structures. Furthermore, a few studies $[3,25]$ demonstrated that fibre orientation along the axis of the tube absorbed more energy than any other orientations. Hence, the pultruded profiles with the circular and square cross sections were considered for this study. The details of the experimental test and its results can be found in ref [1]. To validate the numerical modelling and its approaches the results from the numerical simulations were compared with experimental data [1].

\section{Experimental study}

As explained in the introductory session, an experimental study was conducted [1] to gain the basic understanding of the deformation response and the corresponding energy absorption of pultruded tubes. However, the information related to this numerical study is given here. The circular and square cross sectional glass-polyester tubes were used for the study. All tubes were made with continuous $0^{\circ}$ orientation fibres (Figure 1 (a)) with respect to axis of the tube. Two types of triggering were investigated. The triggering type 1 is the $45^{\circ}$ chamfering around the edges of the tubes (Figure 1(b)) and the type 2 is a tulip pattern with an included angle between the edges of $60^{\circ}$ (Figure 1(c)). Four different tube combinations CP1, CP2, SP1 and SP2 were studied experimentally. The CP1 refers to the circular cross sectional glass-polyester pultruded tube with triggering type 1 . The CP2 refers to the circular cross sectional glass-polyester pultruded tube with triggering type 2. Similarly the SP1 and SP2 refer to the square cross sectional glass-polyester tube with triggering type 1 and 2 respectively. The dimensional details of the tubes are shown in Figure 1 and further details can be found from [1].

The above tube series were studied for three impact velocities (9.3, 12.4 and $14 \mathrm{~m} / \mathrm{s})$ with an impactor mass of $68.85 \mathrm{~kg}$. All tube series (CP1, CP2, SP1 and SP2) exhibited the following four progressive crushing failure modes namely the circumferential delamination, axial cracking, lamina bending and the fibre fracture [1]. After the major circumferential delamination which took place at the mid thickness of the tube, axial cracks were formed only on the outer material along the axis of the tube. As a result the outer plies were subjected to bending and consequently the fracturing of the fibre occurred at the fixed end of the petals. During the bending of laminates a significant amount of multiple delaminations was observed between the sub-laminates .The material splayed inwards showed a progressive folding without any pedalling [1]. For SP1 and SP2 tube series the axial cracks were formed only at the four corners of the square tube due to non-uniform cross section and higher stress concentrations (refer Figure 2). In case of the circular tube due to the uniform profile of the tube a larger number of axial cracks was observed (Figure 2). There was no significant difference in deformation pattern noticed between CP1 and CP2 tube series [1]. Furthermore, both $\mathrm{CP} 1$ and CP2 tube series showed that the lamina bending angle was greater than or equal

\footnotetext{
*Corresponding author: Sivakumar Palanivelu, Tel: +32-(0)9-264.33.15, Fax: +32-(0)9264.35.87

Email: Sivakumar.Palanivelu@UGent.be
} 
to $90^{\circ}$. However, in case of the SP1 and SP2 the bending angle was observed less than or equal to $90^{\circ}[1]$.

\section{Numerical simulation}

\subsection{Salient features of numerical modelling}

The commercially available finite element code ABAQUS V6.7-3 Explicit was used to study the energy absorption characteristics of the pultruded composite tubes. Mamalis [26] investigated the crushing response of the square cross sectional fibre reinforced plastic tubes subjected to static axial compression and impact loading using the shell elements. That simulation work focused on the progressive end crushing with laminate splaying, local tube wall bucking and mid-length collapse. In order to obtain the appropriate failure pattern and the accurate energy absorption prediction of a composite tube, the adaptation of the delamination modelling is important. The interface modelling technique [27] using delamination approach has been tried out in flat plate specimen. A representation of delamination using tiebreak contact interface used for square braided tubes in ref [20]. However, the simulation studies to assess the energy absorption of a composite tube (circular or square) with the delamination approach using cohesive elements have not been conducted in the past. Apart from the mechanical properties and damage mechanism of a composite tube, the peak crushing load of a composite tube is also dependent upon the shape of triggering. In this paper, detailed studies have been conducted to address the numerical modelling issues of triggering mechanisms particularly for the type 1 .

\subsection{Material data}

The mechanical properties of the glass-polyester pultruded tube in principal directions are given in Table 1. For the interface modelling (delamination) between plies, the properties of the polyester resin were considered. The mechanical properties of the polyester resin were adopted from [28].

\subsection{Element used}

As we discussed earlier, when a composite tube is subjected to an axial impact load, it exhibits the delamination, bending of petals, axial cracking and the fibre fracturing modes [1]. The above failure phenomena can be captured by using shell elements. Hence, the pultruded lay-ups were modelled by S4R elements (4-node, quadrilateral, stress/displacement shell element with reduced integration and with finite membrane strain formulation). The meshed shell elements were located at the centre of the thickness of the composite tube. The number of layers of shell elements varied from single to multiple layers. This paper deals with a single layer and two layers of shell elements approach. The approach of multiple layers of shell elements is presented in Part II. The integration points representing all the layers of 0 laminate were located evenly through the thickness of the tubes using Simpson integration rule. A minimum of 3 integration points was located at each layer of shell elements. The material properties of the shell sections in principal directions were defined by introducing a local Cartesian coordinate system for the square tubes and a local cylindrical coordinate system for the circular tubes. 


\subsection{Damage model for composite laminates}

The undamaged orthotropic plane stress material response was specified directly by the elastic stiffness matrix which is given in Table 1. The anisotropic damage model by Hashin and Rotem [23] considers the following four failure modes, (i) fibre rupture in tension (ii) fibre buckling and kinking in compression (iii) matrix cracking under transverse tension and shearing and (iv) matrix crushing under transverse compression and shearing. The same damage model was used for all analyses. The damage initiation criteria have the following forms [29];

$$
\begin{aligned}
& \text { Fibre tension }\left(\hat{\sigma}_{11} \geq 0\right): F_{f}^{t}=\left(\frac{\widehat{\sigma}_{11}}{X^{T}}\right)^{2}+\alpha\left(\frac{\hat{\tau}_{12}}{S^{L}}\right)^{2} \\
& \text { Fibre compression }\left(\hat{\sigma}_{11} \leq 0\right): F_{f}^{c}=\left(\frac{\widehat{\sigma}_{11}}{X^{C}}\right)^{2} \\
& \text { Matrix tension }\left(\hat{\sigma}_{22} \geq 0\right): F_{m}^{t}=\left(\frac{\widehat{\sigma}_{22}}{Y^{T}}\right)^{2}+\left(\frac{\hat{\tau}_{12}}{S^{L}}\right)^{2} \\
& \text { Matrix compression }\left(\hat{\sigma}_{22} \leq 0\right): F_{m}^{c}=\left(\frac{\widehat{\sigma}_{22}}{2 S^{T}}\right)^{2}+\left[\left(\frac{Y^{C}}{2 S^{T}}\right)^{2}-1\right]\left(\frac{\hat{\sigma}_{22}}{Y^{C}}\right)+\left(\frac{\hat{\tau}_{12}}{S^{L}}\right)^{2}
\end{aligned}
$$

In Equation 1, $\alpha$ is a coefficient that determines the contribution of the shear stress to the fibre tensile initiation criterion. The shear stress contribution was taken into account for the tensile failure, so the value of $\alpha$ was taken as 1 . The $\widehat{\sigma}_{11}, \hat{\sigma}_{22}, \hat{\tau}_{12}$ are the components of the effective stress tensor. Then $\widehat{\sigma}$ can be written as

$$
\widehat{\sigma}=M \sigma
$$

where $\sigma$ is the nominal stress and $\mathrm{M}$ is the damage operator, which can be written as

$$
M=\left[\begin{array}{ccc}
\frac{1}{\left(1-d_{f}\right)} & 0 & 0 \\
0 & \frac{1}{\left(1-d_{m}\right)} & 0 \\
0 & 0 & \frac{1}{\left(1-d_{s}\right)}
\end{array}\right]
$$

$d_{f}, d_{m}$ and $d_{s}$ are the damage variables that characterize the fibre, matrix and shear damage which are derived from damage variables $d_{f}^{t}, d_{f}^{c}, d_{m}^{t}$ and $d_{m}^{c}$ corresponding to the four failure modes previously discussed (Equation (1) to (4)) as follows

$$
\begin{array}{r}
d_{f}= \begin{cases}d_{f}^{t} & \text { if } \widehat{\sigma}_{11} \geq 0 \\
d_{f}^{c} & \text { if } \widehat{\sigma}_{11}<0\end{cases} \\
d_{f}= \begin{cases}d_{m}^{t} & \text { if } \widehat{\sigma}_{22} \geq 0 \\
d_{m}^{c} & \text { if } \widehat{\sigma}_{22}<0\end{cases} \\
d_{s}=1-\left(1-d_{f}^{t}\right)\left(1-d_{f}^{c}\right)\left(1-d_{m}^{t}\right)\left(1-d_{m}^{c}\right)
\end{array}
$$

Prior to any damage initiation the damage operator, $\mathrm{M}$, is equal to the identity matrix. Once the damage occurs at any material point for at least one mode, the damage operator becomes

*Corresponding author: Sivakumar Palanivelu, Tel: +32-(0)9-264.33.15, Fax: +32-(0)9- 
significant in the criteria for damage initiation of other modes. The response of the material after damage initiation (describes the rate of degradation of the material stiffness once the initiation criterion is satisfied) is defined by the following equation

$$
\sigma=C(d) \cdot \varepsilon
$$

where $C(d)$ is the damaged elasticity matrix and it can be written as (Equation 9),

$$
C(d)=\frac{1}{D}\left[\begin{array}{ccc}
\left(1-d_{f}\right) E_{1} & \left(1-d_{f}\right)\left(1-d_{m}\right) E_{1} & 0 \\
\left(1-d_{f}\right)\left(1-d_{m}\right) \vartheta_{12} E_{2} & \left(1-d_{m}\right) E_{2} & 0 \\
0 & 0 & D\left(1-d_{s}\right) G
\end{array}\right]
$$

where $D=1-\left(1-d_{f}\right)\left(1-d_{m}\right) \vartheta_{12} \vartheta_{21} ; d_{f}$ reflects the current state of fibre damage; $d_{m}$ reflects the current state of matrix damage; $d_{s}$ reflects the current stage of shear damage; $E_{1}$ is the Young's modulus in the fibre direction; $E_{2}$ is Young's modulus in the matrix direction; $\mathrm{G}$ is the shear modulus and $\vartheta_{12}, \vartheta_{21}$ are Poisson's ratios.

\section{Numerical parametric study}

In order to predict the correct energy absorption and the failure pattern, the numerical simulation should capture the micro-mechanical [9] and the macro-mechanical [30] failure mechanisms of a composite tube. Hence, the different approaches of the numerical modelling to capture the above mechanisms were tried out. The summary of the numerical approach and its results are discussed systematically from simple to complex models.

\subsection{Case 1 - Simulation with a single layer of shell elements}

\subsubsection{Modelling}

Initially, a very basic model which consists of a single layer of shell elements was considered. The advantage of this approach is the reduced computation time. For both the circular and square cross sectional tubes, the tube length of $220 \mathrm{~mm}$ was modelled with a single layer of meshed shell elements and that layer was located at the centre of the thickness of the composite tube. The impactor and bottom crushing plate were modelled as analytical rigid surfaces. An impactor mass of $68.85 \mathrm{~kg}$ was assigned to the centre of the top analytical rigid surface. It was assumed that the thickness of each individual ply of the composite tube is $0.5 \mathrm{~mm}$ for both square and circular tubes. The corresponding material section and its orientation $\left(0^{\circ}\right.$ - along the axis of the tube) were assigned to the shell elements.

Very few quasi-static and impact numerical simulations [10, 31] have been conducted for the triggering type 1 using shell elements. To get the initial peak crushing force the accurate numerical modelling of triggering is very important. Most often the effect of the detailed modelling of triggering on the peak load is not discussed. As described in the Introduction, the modelling of triggering type 1 with solid elements is a straight forward and much more convenient solution than using the shell elements. However, the typical composite tube deformation patterns would be difficult to achieve using the solid elements. Hence, it was decided to continue with the shell elements. Normally the triggering type 1 is modelled with shell elements with gradually reduced thickness [10, 21] as shown in Figure 3(a) (Model A). However, this approach does not yield the correct profile of the triggering 
geometry of the composite tube; rather it would yield a double chamfering triggering geometry. To study the effect of triggering modelling, in addition to the Model A, one more possible modelling (Model B) was adopted where the shell elements are located as shown in Figure 3(b). The complete finite element models of CP1 and CP2 tubes are shown in Figure 4(a) and 4(b). Based on an initial mesh sensitivity study the element size of $3 \mathrm{~mm}$ was chosen for all cases of the tube series. For both the Model A and B, five elements with gradual reduction in thickness were placed vertically at the triggering portion of the tube. Unlike the triggering type 1 , the triggering type 2 can be modelled with shell elements directly due to the constant thickness of the tulips (Figure 4(b)). From these models the effect of delamination and the triggering modelling on the crushing parameters can be studied.

\subsubsection{Adopted boundary conditions and contact controls}

During the experimental testing, the non-triggered end of the composite tube was glued to the bottom end of the impactor due to easier alignment [1]. To simulate the same experimental condition, the non-triggered end of the tube was attached to the top analytical rigid body using "tie" constraints. To simulate the axial impact load only in vertical direction, apart from the vertical translation, all degrees of freedom of the top analytical rigid body were constrained. To represent the fixed crushing plate at the bottom, all the degrees of freedom of the bottom rigid body were also constrained. The "surface-to-surface" masterslave contact algorithm was established between the bottom rigid analytical surface and the composite tube with the friction coefficient equal to 0.2.

\subsubsection{Results}

The analysis was carried out for all cases of tube series involving CP1, CP2, SP1 and SP2 for three impact velocities $(9.3,12.4$ and $14 \mathrm{~m} / \mathrm{s})$. However, due to the similarity in approach, the results are discussed only for the impact velocity of $9.3 \mathrm{~m} / \mathrm{s}$. The deformation of the tube was obtained from the displacement of the top analytical rigid surface and the reaction force was extracted from the interface force between the composite tube and the bottom analytical rigid surface. The results (deformation patterns and the force-deformation curves) obtained from the finite element analysis of the tubes are presented on the basis of triggering classification.

\subsection{3.a. CP1 and SP1 tube series - Triggering type 1}

The sequence of deformation patterns of CP1 tubes at different time intervals for the Model B is given in Figure 5(a). For both circular and square tubes, no significant difference in the deformation pattern was noticed between the Model A and B. However, the deformation pattern of these approaches was entirely different from the experimental deformation pattern. For all three impact velocities of CP1 tubes, the simulation exhibited a local wall buckling failure mode followed by the progressive end collapse (refer Figure 5(a)). For the CP1 tube, the peak crushing load of the Model A shows higher value compared to Model B (refer Figure 6(a)). However, in case of square tube both models yielded approximately the same value (refer Figure 6(b)). In all cases, the deformation length obtained from the numerical analysis was less than the experimental results. This can be clearly noticed from Figure 6(a) and 6(b). Unlike the CP1 tube, the SP1 tube showed an unrealistic ductile deformation that resulted in end crushing and global wall buckling (Figure 5(b)). The maximum deformation of SP1 tube was noticed 11 and $8 \mathrm{~mm}$ for the Model A and

*Corresponding author: Sivakumar Palanivelu, Tel: +32-(0)9-264.33.15, Fax: +32-(0)9- 
$\mathrm{B}$ respectively. From the above results it can be concluded that, both triggering modelling (Model A and B) approaches for CP1 and SP1 tubes were insufficient to capture the correct peak crushing load and the corresponding energy absorption. Furthermore, the numerical modelling with single layer of shell elements was inadequate to capture the delamination phenomenon. The combined effect of these two phenomena (absence of delamination and inadequate triggering modelling) attributed the higher peak crush load.

\subsection{3.b. CP2 and SP2 tube series - Triggering type 2}

The numerical crushing patterns of CP2 and SP2 showed that the tulips experienced the progressive folding at the initial time steps. The cross sectional profile of the tube played a significant role on the tulip folding. In case of the circular tubes, due to the concave profile of the tulip the folding occurred towards the axis of the tube (Figure 7(a)) whereas the tulips of SP2 tube exhibited the outward folding (Figure 7(b)). However the total deformation lengths of both tube series were not comparable with the experimental values. Similar to the experimental results, the triggering type 2 showed two peak loads; the first peak corresponded to the initial folding of the tulip and the second peak occurred during the deformation of the bottom end of the tulip portion of the tube. However, the magnitudes of these two peaks were higher than the experimental results (refer Figure 8(a) and 8(b)). This may be due to the fact that the models were not able to capture the delaminations which occurred at the edges and bottom end of the tulips of the composite tubes during the experimental testing [1]. For SP2 tube the magnitude of the initial peak was very high (Figure 8(b)). This is due to the perfect geometry and the corresponding mesh patterns of tulips. Further study on the effect of (imperfect) geometry on initial peak is discussed in Part II. Similar to CP1 series, the CP2 series also exhibited local wall buckling mode after the crushing of the tulip pattern. The difference in the dissipated energy between the experimental and numerical results was due to the absence of the delamination phenomena. Unlike CP2 tube, there was no local buckling observed in case of SP2 tube. The maximum deformation of the tube was observed till the end of the tulips.

\subsection{Case 2 - Two layers of shell elements with cohesive elements}

\subsubsection{Modelling}

The results from the numerical simulations using a single layer of shell elements showed that modelling the delamination is absolutely necessary to capture the appropriate energy absorption of a composite tube. The numerical simulation of the delamination phenomenon is normally performed by the virtual crack closure technique or using cohesive elements. Using the former approach, the energy release rate can be found out from the nodal displacements and the nodal forces at the crack front. However, this method is very sensitive to the mesh refinement. Hence, in this work the cohesive elements approach was used to model the delamination between the plies. The experimental results provided the evidence of circumferential (multiple) delaminations; out of that the major delamination takes place at the mid of the tube thickness. Hence, the tube was divided into two equal thicknesses which represent the outer and inner sub laminate. Subsequently, the shell elements were located at the centre of each sub-laminate. To model the delamination between the outer and inner sub laminates, a layer of solid cohesive elements was added in between the outer and inner shell layers. The details of the cohesive element are discussed in subsequent sections. Similar to Case 1, an attempt was made to model the correct geometry of triggering type 1 . Two approaches (Model C and D) have been adopted and the details of the numerical modelling 
are shown in Figure 9(a) and 9(b). However, for the triggering type 2, the triggering geometry can be directly captured due to the constant thickness of the tulip.

\subsubsection{Cohesive elements}

The details of the cohesive elements and their constitutive response and the damage model used for this study are discussed in this and the subsequent section. Often the cohesive elements have been used to model the interface bonding where the thickness can be considered zero. The constitutive response [32] of these elements is based on the fracture mechanics approach which considers the amount of energy required to create new fracture surfaces. The behaviour of the interface prior to initiation of damage is often described as linear elastic in terms of a penalty stiffness that degrades under tensile and shear loading. However, the behaviour of these elements is unaffected by pure compression. In order to handle the complex contact conditions between the two (outer and inner) shell layers, a cohesive layer was modelled with zero thickness solid elements COH3D8 (cohesive; three dimensional element with 8 nodes). The traction-separation constitutive response was used which ensures that nominal strains are equal to the relative separation displacement of the cohesive layer. The elastic behaviour is assigned in terms of an elastic constitutive matrix that relates the nominal stresses to the nominal strains across the interface. The nominal stresses are the force components divided by the original area at each integration point, while the nominal strains are the separations divided by the original thickness at each integration point. The nominal traction stress vector," $t$ ", consists of three components $t_{n}$ (normal component), $t_{s}$ and $t_{t}$ (shear components). The corresponding separations are denoted by $\delta_{n}, \delta_{s}$ and $\delta_{t}$. Considering $T_{0}$ the original thickness of the cohesive element, the nominal strains and the elastic behaviour can be written as Equation (10) and (11).

$$
\begin{gathered}
\epsilon_{n}=\frac{\delta_{n}}{T_{0}}, \epsilon_{s}=\frac{\delta_{s}}{T_{0}}, \epsilon_{t}=\frac{\delta_{t}}{T_{0}} \\
t=\left\{\begin{array}{l}
t_{n} \\
t_{s} \\
t_{t}
\end{array}\right\}=\left[\begin{array}{lll}
K_{n n} & K_{n s} & K_{n t} \\
K_{n s} & K_{s s} & K_{s t} \\
K_{n t} & K_{s t} & K_{t t}
\end{array}\right]\left\{\begin{array}{l}
\epsilon_{n} \\
\epsilon_{s} \\
\epsilon_{t}
\end{array}\right\}=K \varepsilon
\end{gathered}
$$

\subsubsection{Damage model used}

The general framework of the damage model using traction-separation consists of three ingredients: a damage initiation criterion, a damage evolution law (the rate at which the material stiffness is degraded once the damage initiation criterion is reached) and finally the choice of the element removal upon reaching a completely damaged state. The damage initiation refers to the beginning of the degradation of the response of any point in the material. In this work, the process of degradation was assumed to occur when a quadratic function involving the nominal stress ratios reaches the value of one (Equation (12)). The Macaulay brackets indicate that the stress state is not valid for pure compressive deformation.

$$
\left\{\frac{\left\langle t_{n}\right\rangle}{t_{n}^{o}}\right\}^{2}+\left\{\frac{t_{s}}{t_{s}^{o}}\right\}^{2}+\left\{\frac{t_{t}}{t_{t}^{o}}\right\}^{2}=1
$$

A typical mode-independent traction-separation with linear softening response was used for this study. As shown in Figure 10, the evolution of the damage can be defined either by the dissipated energy $\left(G_{c}\right)$ due to failure or effective displacement at the failure initiation

*Corresponding author: Sivakumar Palanivelu, Tel: +32-(0)9-264.33.15, Fax: +32-(0)9- 
$\left(\delta_{n}^{0}, \delta_{s}^{0}, \delta_{t}^{0}\right)$ and at complete failure state $\left(\delta_{n}^{f}, \delta_{s}^{f}, \delta_{t}^{f}\right)$. A scalar damage variable "D", captures the overall damage in the material. The initial value of " $D$ " is " 0 ". After the initiation of the damage the value of " $\mathrm{D}$ " can evolve till 1.0, due to further increase of the loading. During the damage process the stress components can be calculated from the following relations,

$$
\begin{gathered}
t_{n}=\left\{\begin{array}{l}
(1-D) \bar{t}_{n}, \bar{t}_{n} \geq 0 \\
\bar{t}_{n} \quad \begin{array}{l}
\text { otherwise }
\end{array}
\end{array}\right. \\
t_{s}=(1-D) \bar{t}_{s} \\
t_{t}=(1-D) \bar{t}_{t}
\end{gathered}
$$

where $\bar{t}_{n}, \bar{t}_{s}$ and $\bar{t}_{t}$ are the stress components calculated by the elastic traction-separation behaviour for the current strains without damage. For the cohesive elements modelling (linear softening response) the properties of polyester resin were considered. The corresponding mechanical properties were adopted from [28].

\subsubsection{Adopted contact algorithm and boundary conditions}

The "tie" constraint involving "surface to surface" discretization method was used to represent the outer shell layer, solid cohesive layer and the inner shell layer as a single entity. The contact algorithm of the tied connection performs the following functions during the analysis. At the time of initial calculation the matching nodes and the adjacent elements are identified. Then during the deformation the matching pairs are constrained to move relative to each other based on the linear elastic and damage displacement law. The same size of the element was chosen for inner shell, outer shell and the solid cohesive layer to ensure the straightforward connection between the master shell elements and the slave cohesive elements (refer Figure 11). Similar to the single layer of shell elements approach (Case 1) the "surface to surface" contact algorithm was used for outer, inner and cohesive layer elements to the bottom analytical rigid surface. In addition to that, the self contact algorithm was also used for all the layers of elements.

\subsubsection{Results}

The numerical simulations were carried out for all tube series with the initial impact velocity of $9.3 \mathrm{~m} / \mathrm{s}$. The computation time for this approach was larger than the previous case. Similar to Case 1, the element size of $3 \mathrm{~mm}$ was chosen for all tube series. The results are presented based on the classification of triggering types.

\subsection{5.a. CP1 and SP1 tube series - Triggering type 1}

For CP1 and SP1, the Model C and D (Figure 9(a) and 9(b)) both were tried out for the impact velocity of $9.3 \mathrm{~m} / \mathrm{s}$. Similar to the results of Case 1, there was no significant difference in the deformation pattern noticed between the Model C and D. Though the delamination was captured between the outer and inner shell layers due to the cohesive elements, the deformation pattern was very similar to the results of the single layer of shell elements. Both tubes (CP1 and SP1) exhibited the local wall buckling mode followed by the progressive end crushing. As an example the CP1 tube is shown in Figure 12. For CP1 tube, 
the two approaches of triggering modelling yielded much higher peak crushing loads (248 and $217 \mathrm{kN}$ for Model C and D respectively) than the experimental value of $78 \mathrm{kN}$. The Model A and B of Case 1 for SP1 yielded the same value of peak crushing load. Hence for SP1 tube the numerical analysis was carried out only for Model D. The magnitude of the peak loads (Figure 13(a) and 13(b)) showed that the finite element modelling of the triggering was not adequate to capture the delamination process and so the correct peak crushing loads. The comparison of the mean crush load and the corresponding energy absorption for all cases are given in Table 2 .

\subsection{5.b. CP2 and SP2 tube series - Triggering type 2}

The deformation sequence of CP2 and SP2 tubes are shown in Figure 14(a) and 14(b) respectively. The Figure 15(a) and 15(b) also show the corresponding energy absorption comparison with the experimental results. The initial increments of CP2 and SP2 tube series showed that the inner and the outer shell layer were subjected to delamination which separated both the outer and inner materials. However, the later stages of these two tubes provided no clear separation of inner and outer materials; rather it showed the progressive end crushing of the tubes. As similar to the experimental results both the tube series showed two peaks; the magnitude of the peak crushing force was approximately $20 \%$ higher than the experimental result. However, these magnitudes are much lower than results from Case 1 (a single layer of shell elements approach). The difference in the experimental and numerical values is shown in Table 2. The average experimental deformation length of CP2 showed approximately $20 \mathrm{~mm}$ higher than the numerical value. On the contrary the numerically predicted deformation length of SP2 tube was $13 \mathrm{~mm}$ higher than the experimental result. The mean crush force of CP2 tube showed the satisfactory result which can be noticed from Figure 15(a). However the SP2 tube yielded a lower mean crush load than the experimental data (refer Table 2). Similar to Case 1, the magnitude of initial peak was higher. The effect of geometric imperfection on the magnitude of initial peak load is discussed in Part II.

\subsection{Comparison of results}

\subsubsection{Comparison of deformation patterns}

From the above numerical parametric study, the approach from Case 1 (a single layer of shell elements) and Case 2 (two layers of shell elements with solid cohesive elements) provided deformation patterns which are entirely different from the experimental results. All tube series (CP1, CP2, SP1 and SP2) exhibited the local wall buckling followed by the end crushing. The initial stages of Case 2 approach yielded a clear evidence of circumferential delamination for the tube series CP2 and SP2. However, other macro failure mechanisms such as axial cracks and bending of plies were not clearly evident.

\subsubsection{Comparison of crush loads and energy absorption}

The comparison of the peak crush load $\left(P_{\max }\right)$, mean crush load $\left(P_{\text {mean }}\right)$, total deformation length $\left(l_{\max }\right)$ and the corresponding energy absorption $\left(E_{d}\right)$ of the experimental and two different approaches (Case 1 and 2) of the numerical simulation are given in Table 2 . The mean crush load $\left(P_{\text {mean }}\right)$ and the absorbed energy $\left(E_{d}\right)$ were calculated based on Equation 16 and 17.

\footnotetext{
*Corresponding author: Sivakumar Palanivelu, Tel: +32-(0)9-264.33.15, Fax: +32-(0)9264.35.87

Email: Sivakumar.Palanivelu@UGent.be
} 


$$
\begin{gathered}
P_{\text {mean }}=\frac{\int_{0}^{l_{\max }} P(l) d l}{l_{\max }}(\mathrm{kN}) \\
E_{d}=\int_{0}^{l_{\max }} P(l) d l \quad(\mathrm{~kJ})
\end{gathered}
$$

where $P(l)$ is the instantaneous crushing load corresponding to the instantaneous crushing deformation length $d l . l_{\max }$ is the maximum or total deformation length. The CP1 and SP1 tubes with a single layer of shell elements approach (Case 1) were not considered for calculating the energy absorption due to the unrealistic peak forces and the deformation lengths. The single shell layer approach for the CP2 and SP2 predicted the higher peak loads and the corresponding energy absorptions. Furthermore, this approach could not predict the correct deformation length of the tubes. As a result the mean crush loads of the tubes were higher than the experimental results. For the Case 2, out of two different approaches for triggering type 1 (Model C and D) the result of the Model D was considered. The comparison of peak crush load between the Cases 1 and 2 provided clear evidence on the influence of delamination on peak crush load for all tube series. This can be clearly noticed for triggering type 2 tube series. Although the peak crush load from the Model D was less than the Model C (Case 2), the magnitude was higher than the experimental result [1]. This gives the clear indication that the modelling of triggering was inadequate to capture the right peak crush load especially for triggering type 1 . The energy absorption of this case for the circular tubes showed the comparable values to the experimental results.

\section{Conclusions}

In this work, a detailed numerical parametric study was conducted to predict the energy absorption characteristics and the corresponding failure patterns of composite tubes. The circular and square cross sectional pultruded profiles made of glass-polyester were considered for this study. Apart from the general conclusion of the energy absorption of different profiles, the numerical modelling was focused to get the reasonable peak crush loads, energy absorption and the corresponding failure patterns of composite tubes. The importance of the delamination modelling on the energy absorption, peak crush load and the failure patterns is also studied using cohesive elements. The influence of triggering modelling on the peak crush load was explained with two different triggering mechanisms ( $45^{\circ}$ edge chamfering and tulip pattern). Two different approaches have been employed (a single layer and two layered shell elements with a solid cohesive layer) to achieve the typical failure modes of brittle composite tubes. From the results of the numerical simulations it can be concluded that:

- The single layer of shell elements approach (Case 1) predicted approximately $140 \%$ and 100\% higher peak crush loads for CP2 and SP2 tubes respectively. For CP2 with triggering type 1 ( $45^{\circ}$ edge chamfering), Model B (triggering modelling approach) provided a lower peak crush load than Model A. However, the magnitude of the peak crush load from these two approaches was much higher than the experimental data. For SP1 tube there was no significant difference in peak load noticed between Model A and B. Furthermore, the deformation patterns of this approach for both triggering cases were entirely different from the experimental deformation patterns. This may be due to the fact that these models were not able to capture the delamination between the plies and inadequate modelling of triggering profile ( $45^{\circ}$ edge chamfering). 
- The two layered shell elements with a solid cohesive layer (Case 2) approach showed clear evidence on the influence of delamination phenomenon on the peak crush load of all composite tube series. The predicted peak crush load for the tube series CP2 and SP2 were $20 \%$ and $30 \%$ higher than the experimental results. The difference may be due to the absence of multiple delaminations. In case of triggering type 1 series (CP1 and SP1) the difference between the experimental and numerical peak crush load was much higher. In addition to the absence of multiple delaminations, the inadequate modelling of triggering contributed to this very high difference. Similar to Case 1 approach the deformation patterns from Case 2 were different from the experimental deformation patterns.

Part II of this paper deals with the importance of considering the multiple delaminations and the correct modelling of triggering to predict the accurate peak crush load and the corresponding energy absorption. These facts have been proved with the approach of multiple layers of shell elements. All the finite elements models using single and two layers of shell elements approach could not be able to predict the axial cracks during crushing. Hence, the numerical simulations were performed with pre-defined seam elements to achieve the appropriate deformation patterns for circular and square composite tubes. The loaddeformation curves of square tube with triggering type 2 (tulip triggering) from two approaches (Case 1 and 2) provided a higher initial peak load. This is due to the perfect geometry of tulips and their corresponding mesh pattern. This fact is proved in Part II by considering the initial geometric imperfections in the numerical model.

\section{Acknowledgements}

The authors gratefully acknowledge the financial support of the "Fund for Scientific Research” - Flanders (F.W.O) (Grant No: B-07674-03).

\section{References}

[1]. Palanivelu, S., Van Paepegem W., Degrieck J., Van Ackeren J., Kakogiannis D., Van Hemelrijck D., Wastiels J. and Vantomme J., Experimental study on the axial crushing behaviour of pultruded composite tubes. Polymer Testing. 29(2): p. 224-234.

[2]. Bolukbasi, A. O. and Laananen D. H., Energy absorption in composite stiffeners. Composites, 1995. 26(4): p. 291-301.

[3]. Farely, G. L., Energy absorption in composite materials Journal of Composite Materials, 1983. 17: p. 167.

[4]. Hamada, H., Coppola J. C., Hull D., Maekawa Z. and Sato H., Comparison of energy absorption of carbon/epoxy and carbon/PEEK composite tubes. Composites, 1992. 23(4): p. 245-252.

[5]. Mamalis, A. G., Robinson M., Manolakos D. E., Demosthenous G. A., Ioannidis M. B. and Carruthers J., Crashworthy capability of composite material structures. Composite Structures, 1997. 37(2): p. 109-134.

[6]. Ramakrishna, S. and Hull D., Energy absorption capability of epoxy composite tubes with knitted carbon fibre fabric reinforcement. Composites Science and Technology, 1993. 49(4): p. 349-356.

[7]. Palanivelu, S., Van Paepegem W., Degrieck J., Kakogiannis D., Van Ackeren J., Van Hemelrijck D., Wastiels J. and Vantomme J., Comparative study of the quasi-static

*Corresponding author: Sivakumar Palanivelu, Tel: +32-(0)9-264.33.15, Fax: +32-(0)9- 
energy absorption of small-scale composite tubes with different geometrical shapes for use in sacrificial cladding structures. Polymer Testing. 29(3): p. 381-396.

[8]. Ramakrishna, S., Microstructural design of composite materials for crashworthy structural applications. Materials \& Design, 1997. 18(3): p. 167-173.

[9]. Mamalis, A. G., Manolakos D. E., Ioannidis M. B. and Papapostolou D. P., The static and dynamic axial collapse of CFRP square tubes: Finite element modelling. Composite Structures, 2006. 74(2): p. 213-225.

[10]. Han, H., Taheri F., Pegg N. and Lu Y., A numerical study on the axial crushing response of hybrid pultruded and +/-45[degree sign] braided tubes. Composite Structures, 2007. 80(2): p. 253-264.

[11]. Mamalis, A. G., Manolakos D. E., Ioannidis M. B. and Kostazos P. K., Crushing of hybrid square sandwich composite vehicle hollow bodyshells with reinforced core subjected to axial loading: numerical simulation. Composite Structures, 2003. 61(3): p. 175-186.

[12]. Bisagni, C., Di Pietro G., Fraschini L. and Terletti D., Progressive crushing of fiberreinforced composite structural components of a Formula One racing car. Composite Structures, 2005. 68(4): p. 491-503.

[13]. Hamada, H., Ramakrishna S. and Satoh H., Crushing mechanism of carbon fibre/PEEK composite tubes. Composites, 1995. 26(11): p. 749-755.

[14]. Mamalis, A. G., Manolakos,D.E., and Viegelahn,G.L, Crashworthy behaviour of thinwalled tubes of fibreglass composite material subjected to axial loading. Journal of Composite Materials, 1990. 24: p. 72.

[15]. Thronton, P. H., Energy absorption in composite structures. Journal of Composite Materials, 1979. 13(247).

[16]. Jimenez. M. A, M. A., Larrode. E, Revuelta. D, Effect of trigger geometry on energy absorption in composite profiles. Composite Structures, 2000. 48(1-3): p. 107-111.

[17]. Fairfull, A. H. H., D., Effect of specimen dimensions on the specific energy absorption of fibre composite tubes. In Proceedings of ICCM-VI, 1987: p. 3.36-3.45.

[18]. Mamalis, A. G., Manolakos D. E., Ioannidis M. B. and Papapostolou D. P., Crashworthy characteristics of axially statically compressed thin-walled square CFRP composite tubes: experimental. Composite Structures, 2004. 63(3-4): p. 347360.

[19]. Solaimurugan, S. and Velmurugan R., Influence of fibre orientation and stacking sequence on petalling of glass/polyester composite cylindrical shells under axial compression. International Journal of Solids and Structures, 2007. 44(21): p. 69997020.

[20]. Mcgregor, C., Vaziri R. and Xiao X., Finite element modelling of the progressive crushing of braided composite tubes under axial impact. International Journal of Impact Engineering. 37(6): p. 662-672.

[21]. Zarei, H., Kröger M. and Albertsen H., An experimental and numerical crashworthiness investigation of thermoplastic composite crash boxes. Composite Structures, 2008. 85(3): p. 245-257.

[22]. LS-DYNA keyword user's manual V971,. LSTC, Livermore,CA, 2006.

[23]. Hashin.Z, R. A. A., A fatigue failure criterion for fiber reinforced materials. Journal of Composite Materials, 1973. 7: p. 448.

[24]. Mamalis, A. G., Manolakos D. E., Ioannidis M. B. and Papapostolou D. P., On the response of thin-walled CFRP composite tubular components subjected to static and dynamic axial compressive loading: experimental. Composite Structures, 2005. 69(4): p. 407-420. 
[25]. Farely, G. L., Effect of fibre and matrix maximum strain rate on the energy absorption of composite materials. Journal of Composite Materials, 1986. 20: p. 322.

[26]. Mamalis, A. G., Manolakos D. E., Demosthenous G. A. and Ioannidis M. B., The static and dynamic axial crumbling of thin-walled fibreglass composite square tubes. Composites Part B: Engineering, 1997. 28(4): p. 439-451.

[27]. Iannucci, L., Progressive failure modelling of woven carbon composite under impact. International Journal of Impact Engineering, 2006. 32(6): p. 1013-1043.

[28]. Warrior, N. A., Turner T. A., Robitaille F. and Rudd C. D., Effect of resin properties and processing parameters on crash energy absorbing composite structures made by RTM. Composites Part A: Applied Science and Manufacturing, 2003. 34(6): p. 543550.

[29]. ABAQUS User manual. ABAQUS, Inc. and Dassault Systèmes, 2007.

[30]. Arnaud, P. and Hamelin P., Dynamic characterization of structures: A study of energy absorption in composite tubes. Composites Science and Technology, 1998. 58(5): p. 709-715.

[31]. Mamalis, A. G., Manolakos,D.E., Ioanniddis, M.B., and Papapostolou, Finite element modelling of the crushing response of square carbon FRP tubes subjected to static and dynamic axial compression. WIT Transactions on Engineering Sciences, 2005. 49(Impact Loding of Lightweight structures): p. 373-386.

[32]. ABAQUS Theory manual. ABAQUS, Inc. and Dassault Systèmes, 2007.

*Corresponding author: Sivakumar Palanivelu, Tel: +32-(0)9-264.33.15, Fax: +32-(0)9- 


\section{FIGURES AND CAPTIONS}

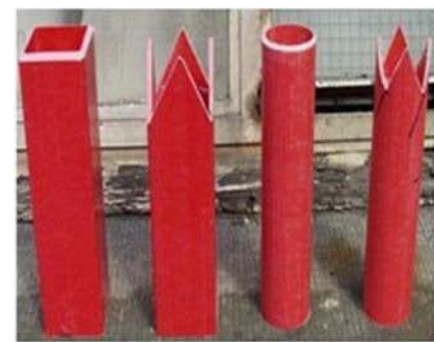

Length $=220 \mathrm{~mm}$

(a) Test specimens

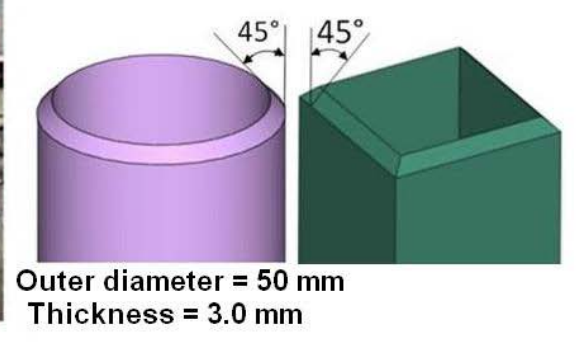

(b) Triggering type 1

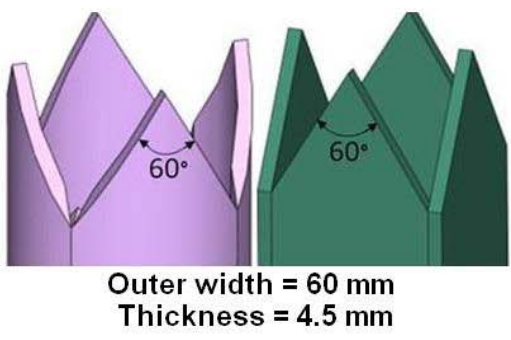

(c) Triggering type 2

Figure 1: Composite tube test specimens and its triggering details.

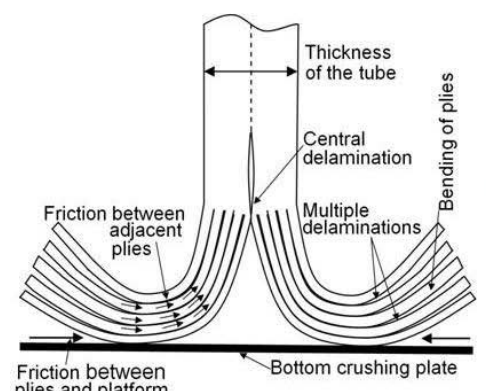

Friction between
plies and platform

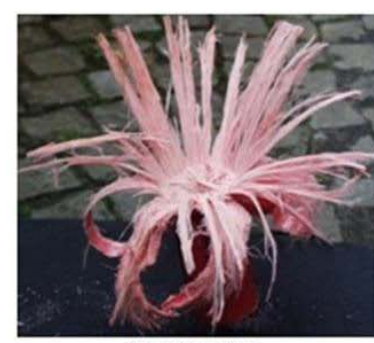

CP1 tube

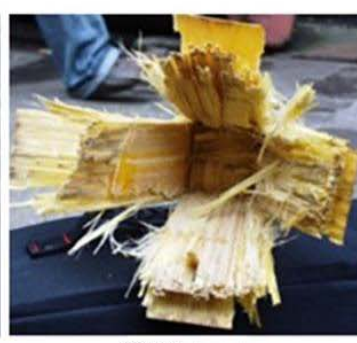

SP1 tube

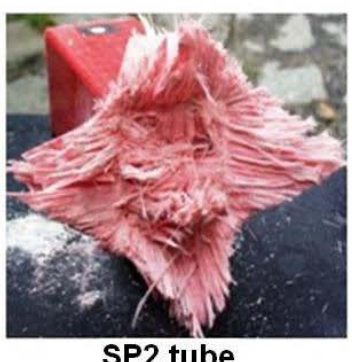

SP2 tube

Figure 2: Experimental deformation patterns of different composite tube series [1].

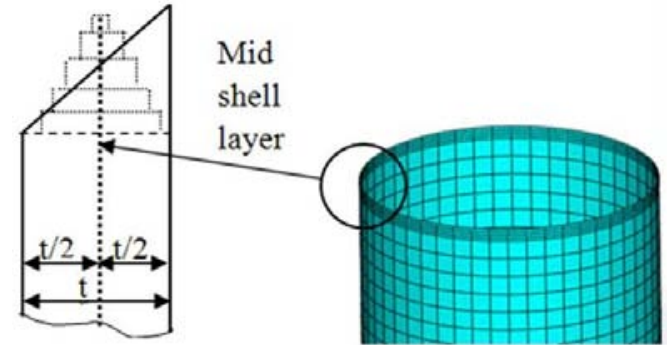

(a) Triggering type 1 - Model A

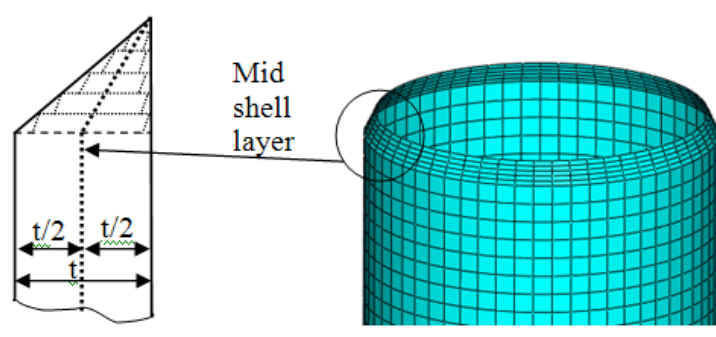

(b) Triggering type 1 - Model B

Figure 3: Finite element modelling of triggering type 1. 


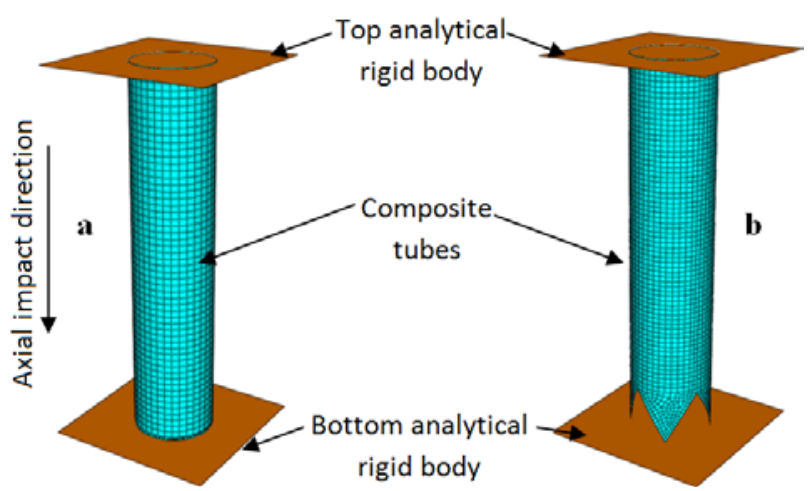

Figure 4: Finite element modelling with a single layer of shell elements (a) CP1 tube (Model A) (b) CP2 tube.
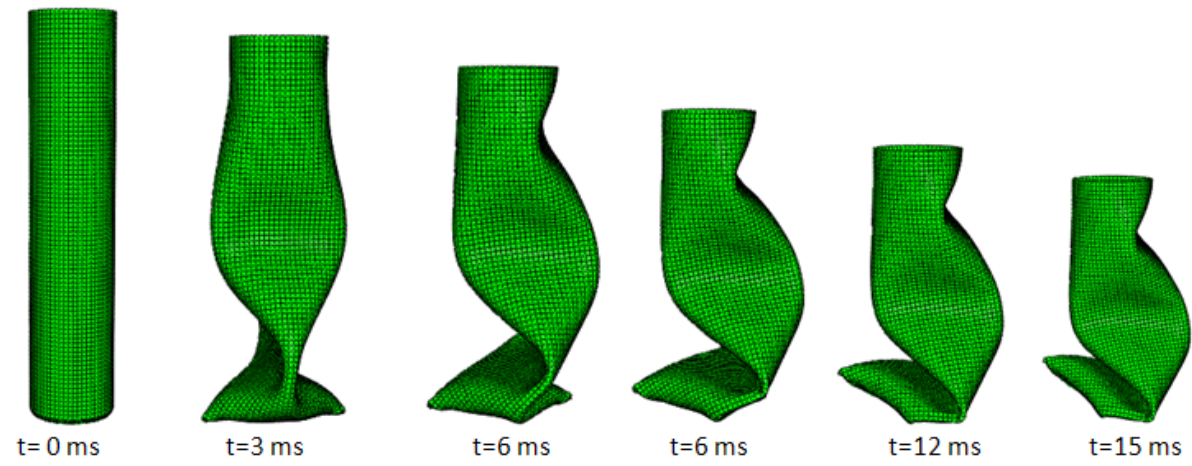

(a) CP1 tube with a single layer of shell elements - Model B
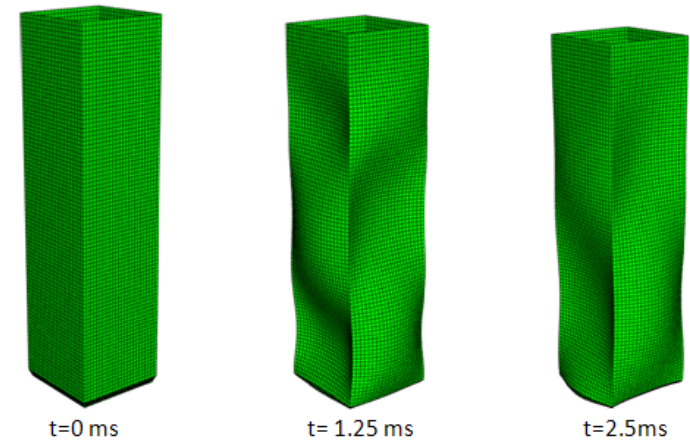

(b) SP1 tube with a single layer of shell elements

Figure 5: Deformation sequence of CP1 and SP1 tubes with a single layer of shell elements.

*Corresponding author: Sivakumar Palanivelu, Tel: +32-(0)9-264.33.15, Fax: +32-(0)9- 


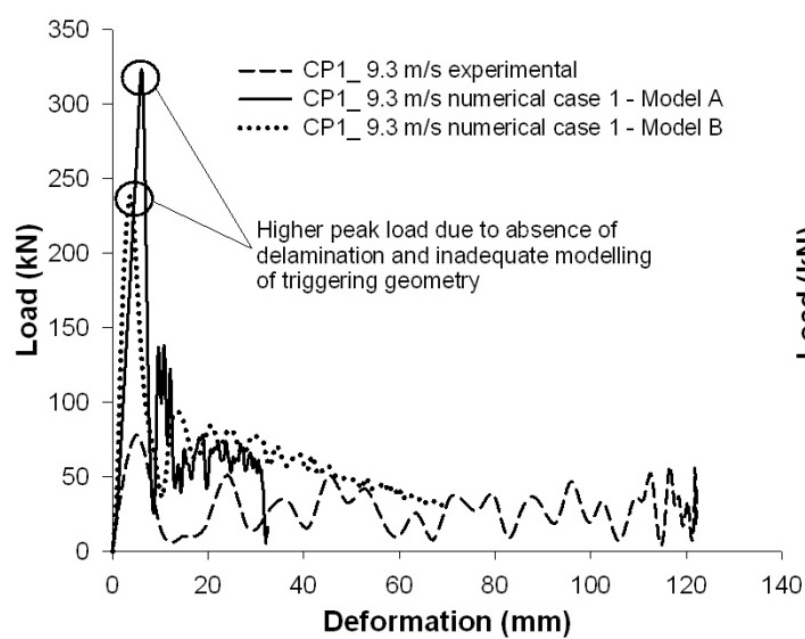

(a) CP1 tube with a single layer of shell elements

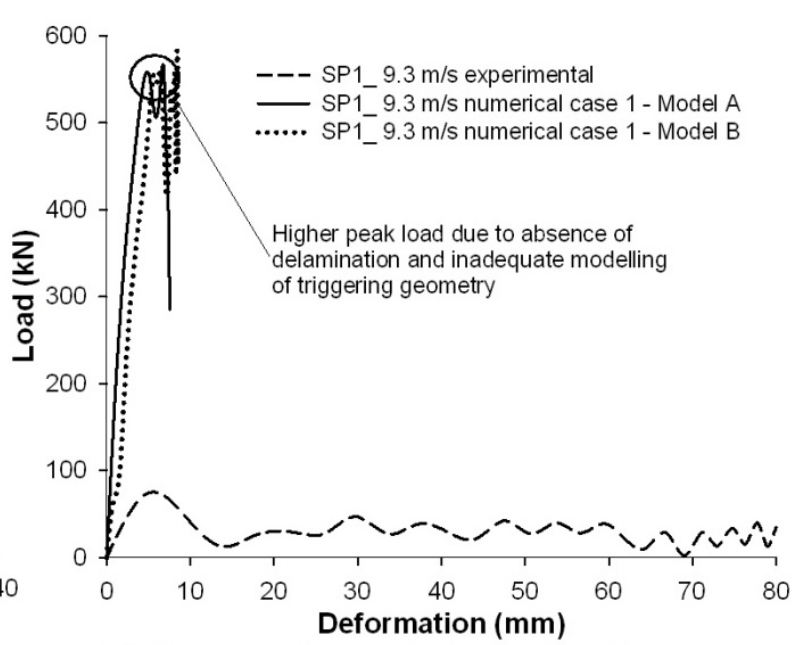

(b) SP1 tube with a single layer of shell elements

Figure 6: Comparison of load-deformation curve of CP1 and SP1 tubes with a single layer of shell elements.
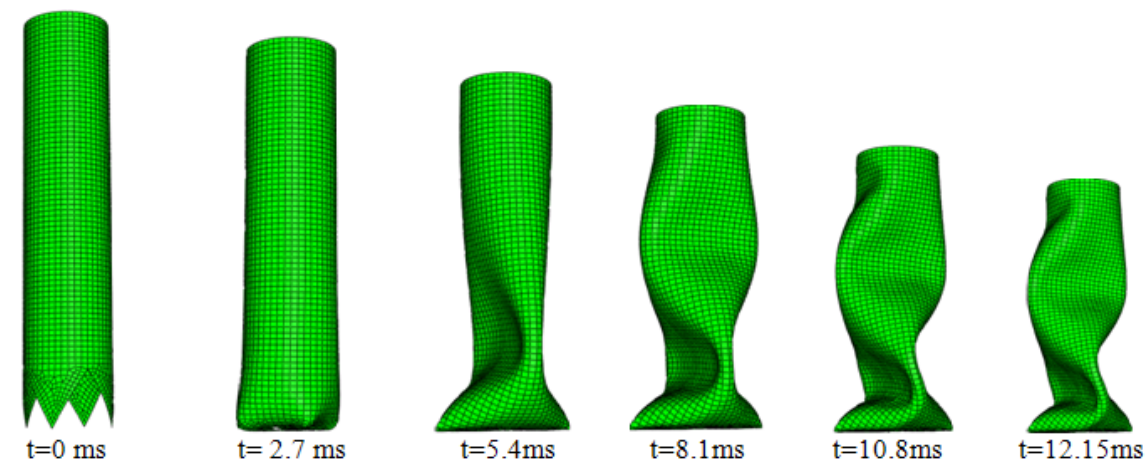

(a) CP2 tube with a single layer of shell elements.
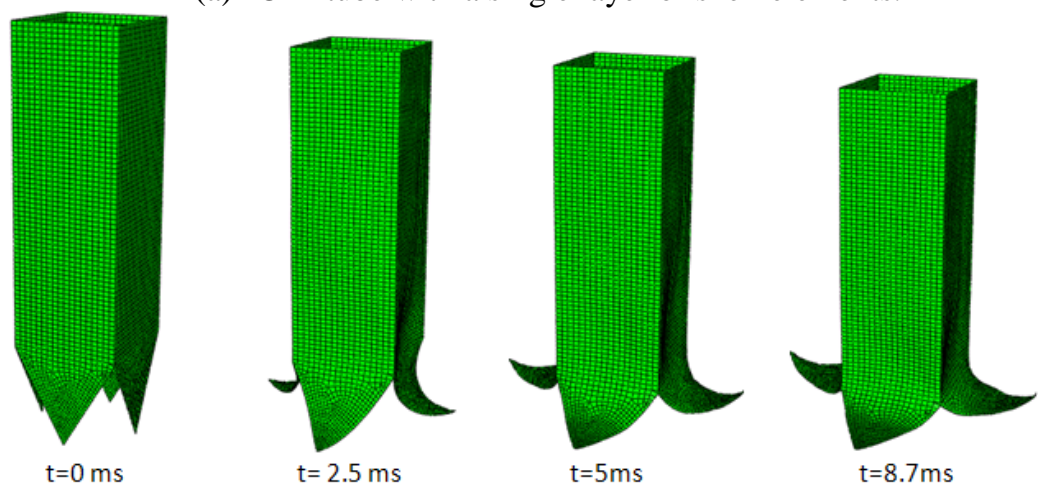

(b) SP2 tube with a single layer of shell elements.

Figure 7: Deformation sequence of CP2 and SP2 tubes with a single layer of shell elements. 


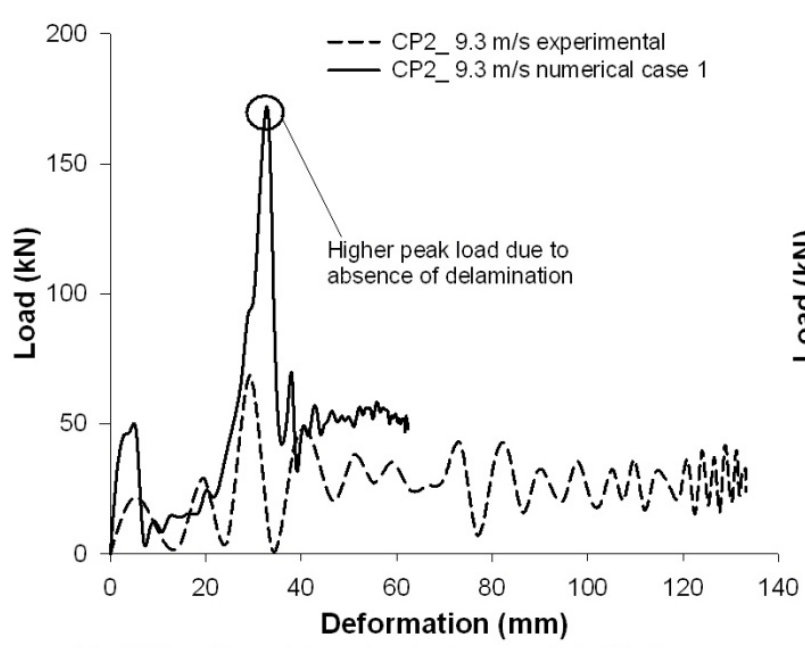

(a) CP2 tube with a single layer of shell elements

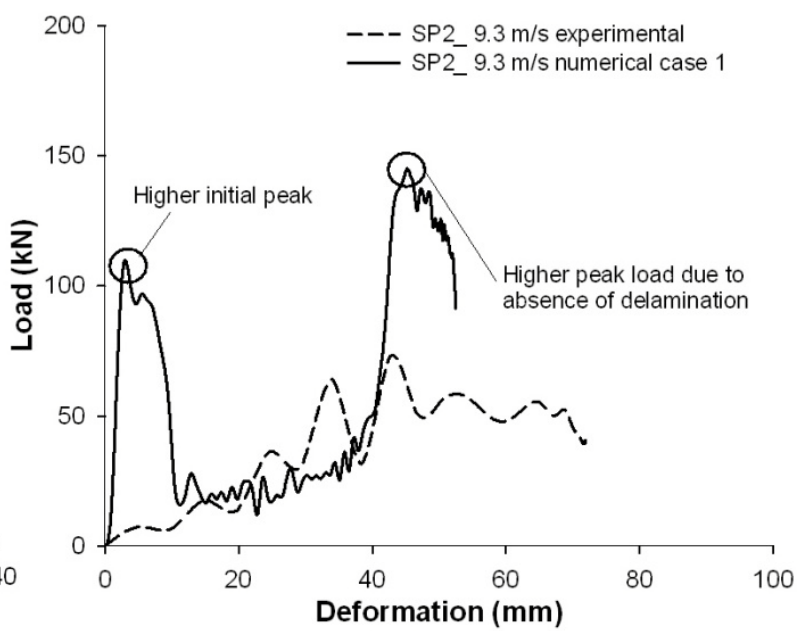

(b) SP2 tube with a single layer of shell elements

Figure 8: Comparison of load-deformation curve of CP2 and SP2 tubes with a single layer of shell elements.

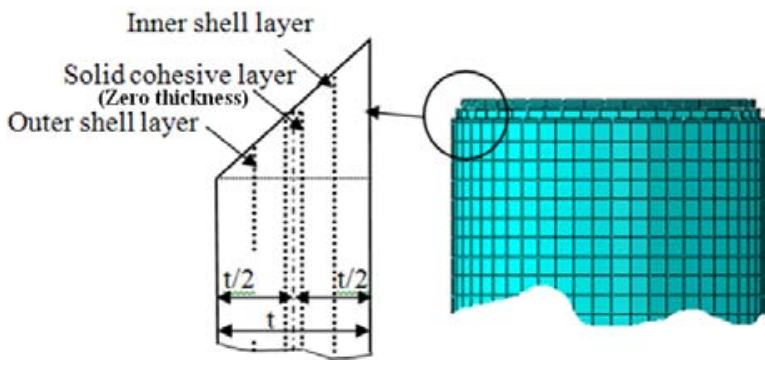

(a) Model C

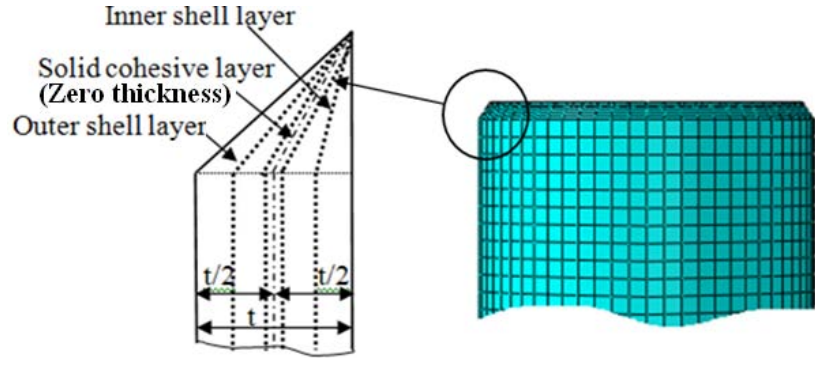

(b) Model D

Figure 9: Finite element modelling of CP1 tube with two layers of shell elements and a solid cohesive layer.

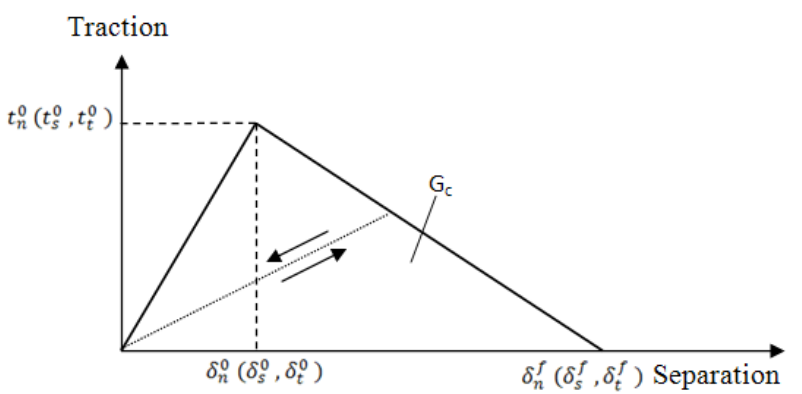

Figure 10: Traction-separation with linear softening response.

*Corresponding author: Sivakumar Palanivelu, Tel: +32-(0)9-264.33.15, Fax: +32-(0)9- 


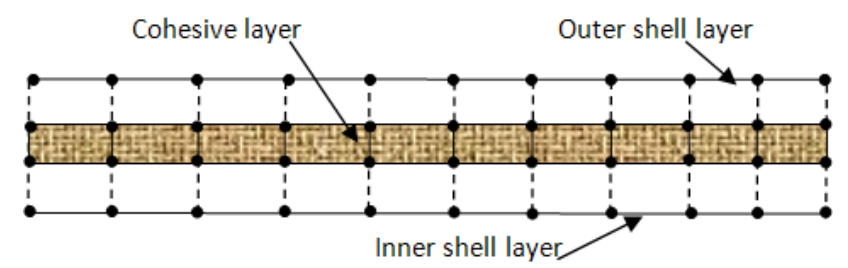

Figure 11: Tied connection between the shells and a cohesive layer.
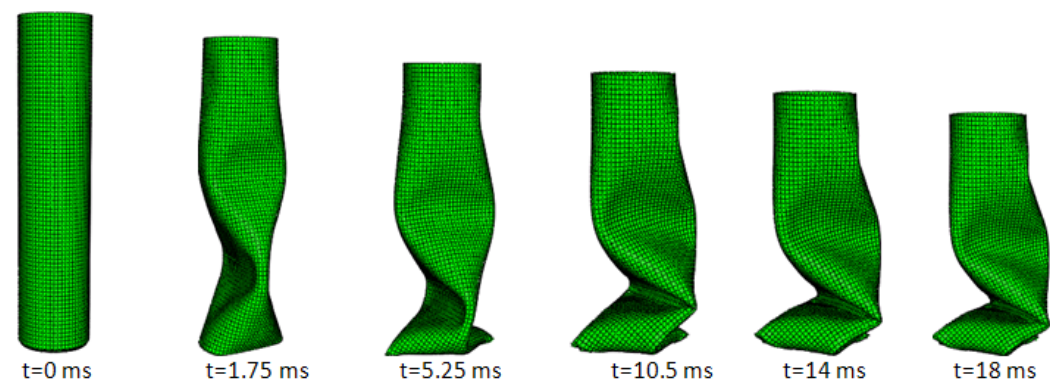

Figure 12: Deformation sequence of CP1 tube with two layers of shell elements and a solid cohesive layer.

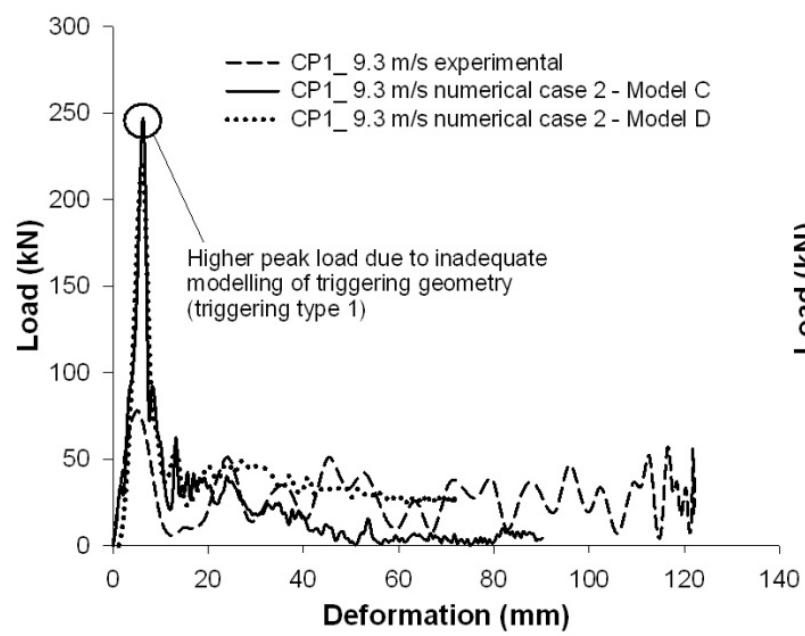

(a) CP1 tube with two layers of shell elements and a solid cohesive layer

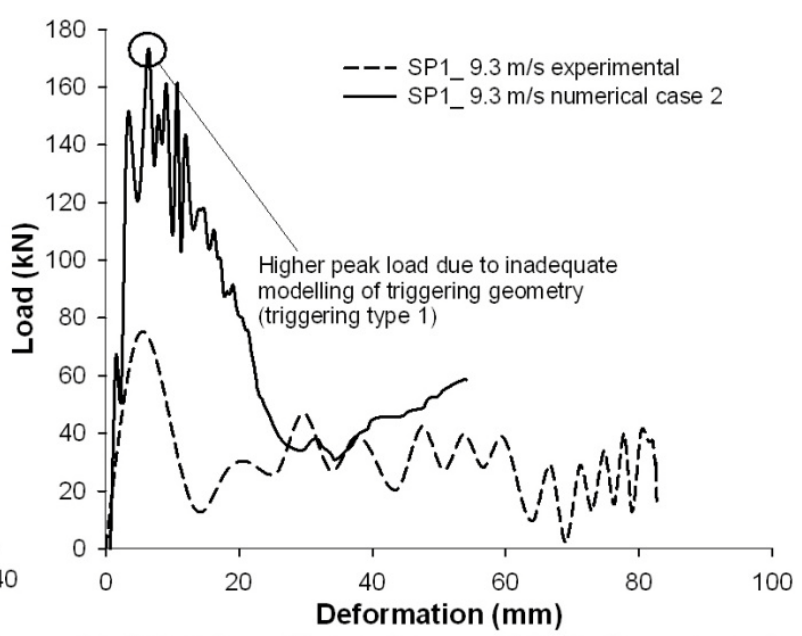

(b) SP1 tube with two layers of shell elements and a solid cohesive layer

Figure 13: Comparison of load-deformation curve of CP1 and SP1 tubes with two layers of shell elements and a solid cohesive layer. 

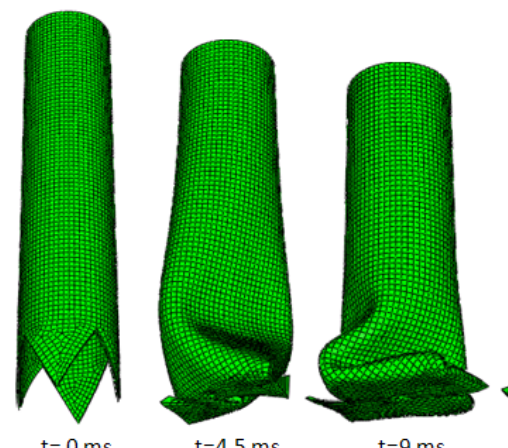

$\mathrm{t}=9 \mathrm{~ms}$

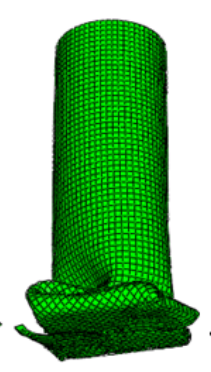

$\mathrm{t}=13.5 \mathrm{~ms}$

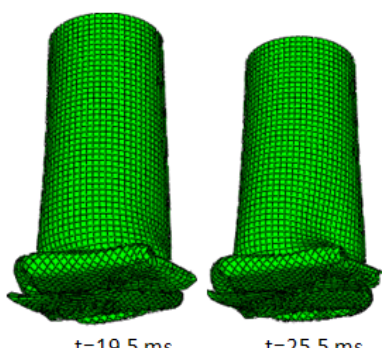

$\mathrm{t}=19.5 \mathrm{~ms}$

$\mathrm{t}=25.5 \mathrm{~ms}$

(a) CP2 tube with two layers of shell elements and a solid cohesive layer

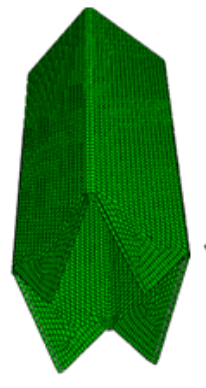

$\mathrm{t}=0 \mathrm{~ms}$

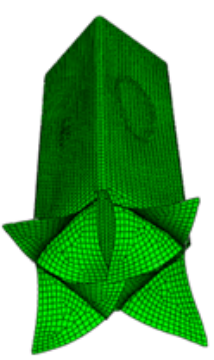

$\mathrm{t}=2.8 \mathrm{~ms}$

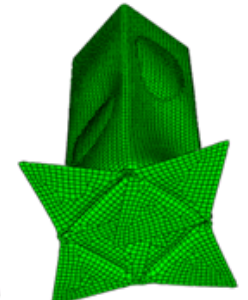

$\mathrm{t}=5.6 \mathrm{~ms}$

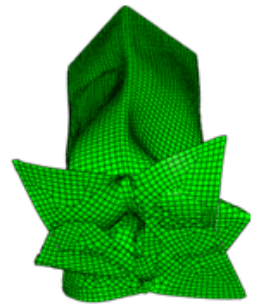

$\mathrm{t}=9.8 \mathrm{~ms}$

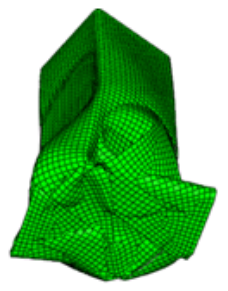

$\mathrm{t}=13 \mathrm{~ms}$

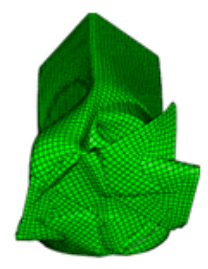

$\mathrm{t}=18 \mathrm{~ms}$

(b) SP2 tube with two layers of shell elements and a solid cohesive layer

Figure 14: Deformation sequence of CP2 and SP2 tube with two layers of shell elements and a solid cohesive layer.

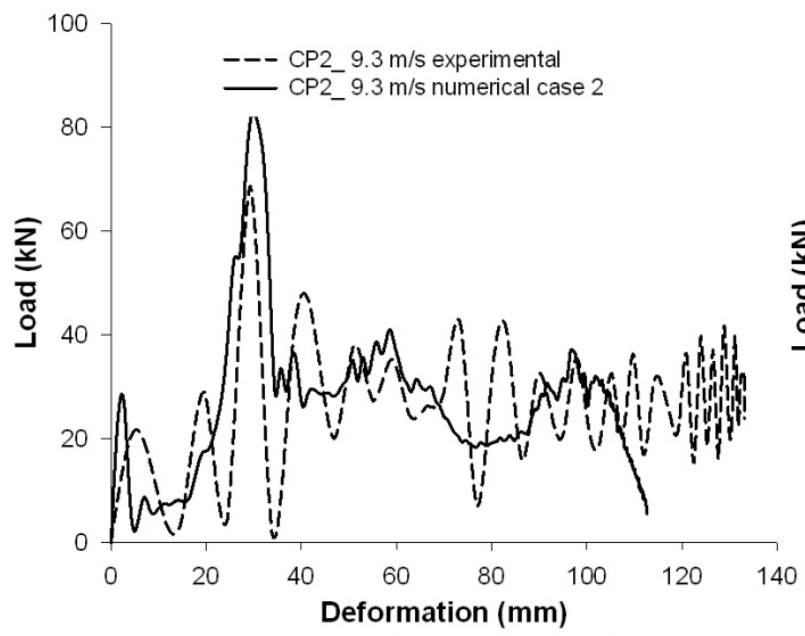

(a) CP2 tube with two layers of shell elements and a solid cohesive layer

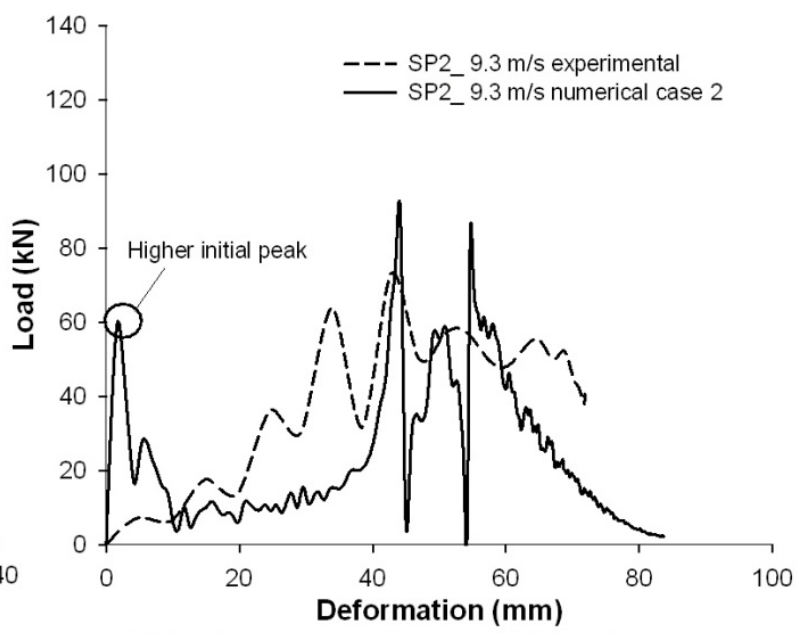

(b) SP2 tube with two layers of shell elements and a solid cohesive layer

Figure 15: Comparison of load-deformation curve of CP2 and SP2 tube with two layers of shell elements and a solid cohesive layer.

*Corresponding author: Sivakumar Palanivelu, Tel: +32-(0)9-264.33.15, Fax: +32-(0)9- 


\section{TABLES}

Table 1: Material properties of the glass polyester pultruded composite tube in principal directions.

\begin{tabular}{|c|c|c|}
\hline Parameters & Symbol & Values \\
\hline \multicolumn{3}{|c|}{ Material and elastic data } \\
\hline Density $\left(\mathrm{kg} / \mathrm{m}^{3}\right)$ & $\rho$ & 1850 \\
\hline Longitudinal modulus (GPa) & $E_{11}$ & 33.5 \\
\hline Transverse modulus (GPa) & $E_{22}$ & 8.0 \\
\hline In-plane shear modulus (GPa) & $\mathrm{G}_{12}$ & 5.0 \\
\hline Out-of-plane shear modulus (GPa) & $\mathrm{G}_{23}$ & 5.5 \\
\hline \multirow[t]{2}{*}{ Poisson's ratio } & $v_{12}$ & 0.29 \\
\hline & $v_{23}$ & 0.32 \\
\hline \multicolumn{3}{|c|}{ Glass polyester composite Strength } \\
\hline Longitudinal tensile strength (MPa) & $\mathrm{X}^{\mathrm{T}+\mathrm{m}}$ & 400 \\
\hline Longitudinal compressive strength $(\mathrm{MPa})$ & $\mathrm{X}^{\mathrm{C}}$ & 200 \\
\hline Transverse tensile strength (MPa) & $\mathrm{Y}^{\mathrm{T}}$ & 30 \\
\hline Transverse compressive strength (MPa) & $\mathrm{Y}^{\mathrm{C}}$ & 50 \\
\hline In-plane shear strength (MPa) & $S^{L}$ & 30 \\
\hline Out of plane shear strength (MPa) & $\mathrm{S}^{\mathrm{T}}$ & 30 \\
\hline
\end{tabular}

Table 2: Comparison of experimental and numerical simulation results.

\begin{tabular}{|c|c|c|c|c|c|c|c|c|c|c|c|c|c|c|c|c|}
\hline \multirow{2}{*}{ Cases } & \multicolumn{4}{|c|}{$\begin{array}{c}\text { Peak crush load (kN) } \\
P_{\max }\end{array}$} & \multicolumn{4}{|c|}{$\begin{array}{c}\text { Mean crush load (kN) } \\
P_{\text {avg }} \\
\end{array}$} & \multicolumn{4}{|c|}{$\begin{array}{c}\text { Deformation length (mm) } \\
I_{\max }\end{array}$} & \multicolumn{4}{|c|}{$\begin{array}{c}\text { Absorbed energy (kJ) } \\
E_{d}\end{array}$} \\
\hline & ôे & $\hat{U}$ & $\vec{\omega}$ & 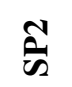 & Q & $\tilde{U}$ & $\vec{\omega}$ & กิ & $\overline{0}$ & $\tilde{u}$ & $\bar{n}$ & $\tilde{\omega}$ & $\overrightarrow{0}$ & $\tilde{u}$ & $\vec{\omega}$ & $\tilde{\omega}$ \\
\hline $\begin{array}{c}\text { Experimental } \\
{[1]}\end{array}$ & 78 & 69 & 73 & 73 & 28.3 & 26.0 & 31.1 & 37.7 & 122 & 133 & 82.5 & 71 & 3.46 & 3.47 & 2.56 & 2.68 \\
\hline $\begin{array}{c}\text { Numerical } \\
\text { Case } 1\end{array}$ & 238 & 165.8 & 554 & 145 & - & 47.7 & - & 56.0 & - & 62.3 & - & 52.5 & - & 2.99 & - & 2.971 \\
\hline $\begin{array}{c}\text { Numerical } \\
\text { Case } 2\end{array}$ & 217 & 82.5 & 171 & 95 & 33.3 & 27.3 & 70.4 & 24.0 & 91 & 113 & 54 & 84 & 3.03 & 3.08 & 3.80 & 2.01 \\
\hline
\end{tabular}

